\title{
The effect of GPS refresh rate on measuring police patrol in micro-places
}

\author{
Oliver K. Hutt ${ }^{*}$ (D, Kate Bowers and Shane D. Johnson
}

\begin{abstract}
With the increasing prevalence of police interventions implemented in micro hot-spots of crime, the accuracy with which officer foot patrols can be measured is increasingly important for the robust evaluation of such strategies. However, it is currently unknown how the accuracy of GPS traces impact upon our understanding of where officers are at a given time and how this varies for different GPS refresh rates. Most existing studies that use GPS data fail to acknowledge this. This study uses GPS data from police officer radios and ground truth data to estimate how accurate GPS data are for different GPS refresh rates. The similarity of the assumed paths are quantitatively evaluated and the analysis shows that different refresh rates lead to diverging estimations of where officers have patrolled. These results have significant implications for the measurement of police patrols in micro-places and evaluations of micro-place based interventions.
\end{abstract}

Keywords: Police patrol, GPS, Micro-places

\section{Introduction}

Police patrols are often targeted at areas of above-average risk of crime occurring-areas known as crime hot-spots. These patrols are generally acknowledged to be effective (Braga et al. 2019), though how effective they can be and how to optimise patrol strategies remains a topic for debate. A critical issue with measuring the effectiveness of police patrols lies in the accurate measurement of patrols themselves. Throughout the Twentieth century there existed only two practical methods for measuring where and when officers were on patrol: asking officers to record when they entered or exited a hot-spot, or deploying additional observers to record this information instead. Both methods require an additional resource burden to be met and are subject to various sources of error.

More recently a third and far less labour-intensive alternative has become possible: the use of Global Positioning System (GPS) data collected from officer-worn radios. Several studies have now used GPS data to measure police patrols (Ariel et al. 2016; Williams and Coupe 2017) and they make a necessary and welcome addition to the literature. While the use of GPS data to measure patrols holds many advantages over the previous methods a question remains: how accurate is that measurement? A critical contributing factor to this question is how often the GPS data are recorded on a given patrol. Due to limitations associated with police radio batteries, it is not feasible to confirm an officer's location every second or even every $10 \mathrm{~s}$, and so the frequency with which an officer's location is measured (in the form of a GPS 'ping') will affect how accurately their true patrol path can be estimated. Based on conversations with several UK police services ${ }^{1}$ the standard 'refresh rate' for officer-worn radios is between 2 and $5 \mathrm{~min}$ and their path between these pings must be interpolated in order to estimate their patrol routes. This is becoming particularly relevant as patrol areas are being designated at

*Correspondence: o.hutt.12@ucl.ac.uk

Department of Security and Crime Science, UCL, 35 Tavistock Square, London WC1H 9EZ, UK

\footnotetext{
${ }^{1}$ Including but not limited to Thames Valley Police and the Metropolitan Police Service, London.
} 
more granular spatial and temporal resolutions; down to hot-spots that measure only a few $100 \mathrm{~m}$ across and that are 'hot' for less than a day (see Mohler et al. 2015, for an example).

This paper presents two experiments which attempt to measure the accuracy of GPS data under real-life conditions. The first experiment was conducted with a police force in the North of England to verify how accurately a GPS ping from an officer-worn radio represented the true location of the officer at the time the ping was recorded. The second experiment was conducted with the Metropolitan Police Service (MPS) London and used a faster than standard ping refresh rate in order to measure how different refresh rates impacted on the assumed paths which officers took (and thus would influence the estimate police patrol time in crime hot-spots).

The rest of this section provides an overview of the police patrol literature with a particular focus on how it has been measured. This is followed by the first experiment which demonstrates that GPS data do in most cases accurately represent the officer's location at the point of measurement and thus provide an adequate basis from which to try and interpolate their complete path. The second experiment interpolates different officer patrol paths by sampling from the GPS data at different rates. A similarity metric is then used to compare how far apart an officer's assumed path would be based on different GPS refresh rates. The final section discusses how the results of these experiments have implications for both past and future research.

\section{Measuring police patrol}

Whilst it is now accepted that hot-spot policing can reduce crime, a question that remains is how much time should officers spend in a hot-spot to maximise efficiency and effectiveness? Research focussed on the relationship between the amount of time police officers spend in a hot-spot-also called dosage-and the benefits produced remains sparse (Bowers et al. 2004). There are some notable studies, such as an analysis by Koper (1995) of a preventative patrol experiment conducted in Minneapolis (Sherman and Weisburd 1995). The work was based on the recordings of trained observers who were positioned in 100 active hot-spots; they recorded the length of time officers spent in the hot-spot and the crime and disorderly behaviour in and around it. Koper found that fewer than $10 \mathrm{~min}$ of police presence had no noticeable improvement in deterrence when compared to a quick drive-by. $15 \mathrm{~min}$ of police presence did have an effect but more than 15 min had diminishing returns. However, he cautioned about interpreting the results as definitive as the effect was not statistically significant. This peak in efficiency at $15 \mathrm{~min}$ (known as the 'Koper Curve') has become a 'golden rule' in preventative patrol (Perry et al. 2013), despite a lack of further study. Separate studies have tested whether 15-min patrols are effective (e.g. Telep et al. 2014) and found this can lead to a significant reduction in crime, but the effect of different amounts of dosage have received little scrutiny.

One reason for this is the significant challenge associated with quantifying exactly how long officers spend in hot-spots. Until recently, this could only realistically be achieved with very laborious methods: stationing observers within a hot-spot (e.g. Koper 1995); asking police officers to record exactly when they entered and exited the area (e.g. Ratcliffe et al. 2011; Sherman and Weisburd 1995); or analysing police logs (e.g. Telep et al. 2014). The alternative has been to assume that treatment had occurred without actually measuring it. However, the fact that the patrols are assumed to take place in the correct locations, rather than being empirically measured, is an inherent weakness of such a study due to the potential for implementation failure as was observed in the studies by Sherman et al. (1989), Sherman and Weisburd (1995) and Telep et al. (2014). A failure to deliver what was planned in full or in part is a frequent problem in crime prevention practice (see Knutsson and Clarke 2006), and means that activity realised in practice may differ substantially from what was intended. This has the potential to undermine studies which adopt an 'intention-to-treat' evaluation model (e.g. Andresen and Hodgkinson 2018; Novak et al. 2016), where implementation activity is assumed but not measured and highlights the importance of directly measuring policing dosage.

The quantification of dosage has been and remains a considerable challenge. Even when observers or police logs are used, there are often issues of precision; officers can stray outside the patrol zone without realising it (Sorg et al. 2014) or ...through boredom or a perception that they were displacing crime to nearby streets would stray for a time if they were aware of areas of interest just beyond the foot patrol area... (Ratcliffe et al. 2011). Since Koper's 1995 study, few studies have looked at how the amount of police patrol dosage impacts on crime. As patrols are directed to increasingly small micro-areas, it follows that the measurement of patrols needs to be increasingly precise and this remains a challenge. However, there has been a steady growth in the usage of GPS devices by police forces. These provide a new method for tracking where officers move and thus a new way of estimating police dosage. The next section discusses the strengths and weaknesses of this approach along with an overview of the few studies which have so far utilised these data. 


\section{Using GPS data}

The growth in usage of GPS devices by police forces provides a capability for tracking where officers move with much greater accuracy than has previously been possible. Potentially the first study to utilise GPS data to measure dosage was conducted in Peterborough (UK) using radio data for the movement of Police Community Support Officers (PCSO) (Ariel et al. 2016). In that study, GPS pings were recorded every minute, and the dosage in a hot-spot was measured as the time between the first GPS ping within the hot-spot, and the first ping without. This study found that police patrols had a significant impact upon crime and disorder, with patrols lasting up to around $15 \mathrm{~min}$ and on average lasting around $8 \mathrm{~min}$. However, in the analysis conducted, patrol dosage was measured in the aggregate over the entire study period, meaning that variation in patrol dosage per day, or per police shift, was not considered.

Williams and Coupe (2017) also measured police patrol dosage using GPS data. Specifically, the study was concerned with whether more frequent but shorter periods of patrol dosage (nine periods of 5 min each) had a greater or lesser impact on crime than less frequent but longer (three periods of $15 \mathrm{~min}$ ) patrols. The 'crackdown, back off' theory hypothesised by Sherman (1990) stated that the deterrent effect generated by police patrols 'decays' once there is no police presence. Williams and Coupe hypothesised that more frequent patrols, "might arguably allow less time for what Sherman calls "deterrence decay" to kick in, so that there would be less crime." However, their findings suggest that the longer, less frequent patrols were more effective at preventing crime.

GPS data are not a panacea for measuring police patrols and do come with some drawbacks. Chief among these is the fact that signals do not account for every step in an officer's path. In their study, Ariel et al. (2016) were able to use 1-min refresh rates. However, as mentioned earlier, the standard ping rate (at least for patrol officer radios) is generally every 2 to 5 min due largely to data collection costs and radio battery life considerations. Williams and Coupe (2017) did not report the time between GPS pings in their study. Given the delays between the recording of foot-patrol locations (even if this is only $1 \mathrm{~min}$ ), the paths taken between GPS pings require interpolation. If employed as a micro-level measure of dosage, this can introduce errors into patrol evaluations (which will increase with the latency between GPS pings).

Vehicle-based police patrols are less likely to be impacted by the GPS issues discussed for two key reasons. First, Automated Vehicle Locator (AVL) GPS pings usually occur much more frequently; either every 10 to $15 \mathrm{~s}$ or every few $100 \mathrm{~m}$ of travel (for an example, see Weisburd et al. 2015) both because a vehicle is likely to be travelling much faster than a person on foot and because battery life is less of a concern when the GPS device is installed in a vehicle. Second, vehicles are confined to the road network and as such their potential paths between pings are much more restricted and thus easier to interpolate accurately when compared to foot-based officers who have no such restriction. Map-matching algorithms seek to turn GPS data into digitised complete paths and mitigate the measurement errors inherent in GPS data. A large number of map-matching algorithms now exist though none is recognised as 'the best' (Houda 2016). In part this is due to the requirements of the algorithms and the input data. Algorithms perform better or worse dependent on street network densities and the rate of data collection (the sample rate), and the computational power available can limit the complexity of the algorithm in use. The use-case can also have a significant impact on which algorithms can be used, for instance, whether all data are historic (allowing the algorithm to 'look ahead' in the data) or whether data input is in real time (also known as off-line and on-line models). For this reason, although we focus our attention on foot-based patrol dosage we remain mindful that the issues discussed may also occur, albeit in a more limited way, for vehicle-based patrols.

Another concern with GPS data is that systematic bias can exist within GPS location measurements and come from various sources; satellite orbital errors and clock bias, receiver clock errors, refraction in the ionosphere and troposphere, and signal multipath (He et al. 2011). Whilst there are methods for reducing or removing most of these errors, signal multipath-where the signal between the satellite and receiver is reflected by large objects, causing non-direct paths to be taken-is distinctly problematic. Within an urban environment this is known as an 'urban canyon' issue; whereby tall buildings (or other structures) interfere with the GPS tracking system, causing it to incorrectly interpolate the location as signals are reflected off of buildings, (see Fig. 1). A study in the town of Gorlitz, Germany found that the average measurement error in areas with broad streets and few tall buildings was $2.5 \mathrm{~m}$, whilst areas with narrow streets and mostly tall buildings had a average measurement error of $15.4 \mathrm{~m}$ (Modsching et al. 2006). Despite these challenges, GPS data provide a valuable method by which patrol data could be more accurately computed than was possible using previous methods.

This paper is motivated by a desire to quantify footpatrol measurement errors when GPS data are the basis of that measurement. What follows is an investigation of how significantly measurement errors might impact on the estimation of police dosage in micro-places and thus evaluations that try to account for police dosage. 


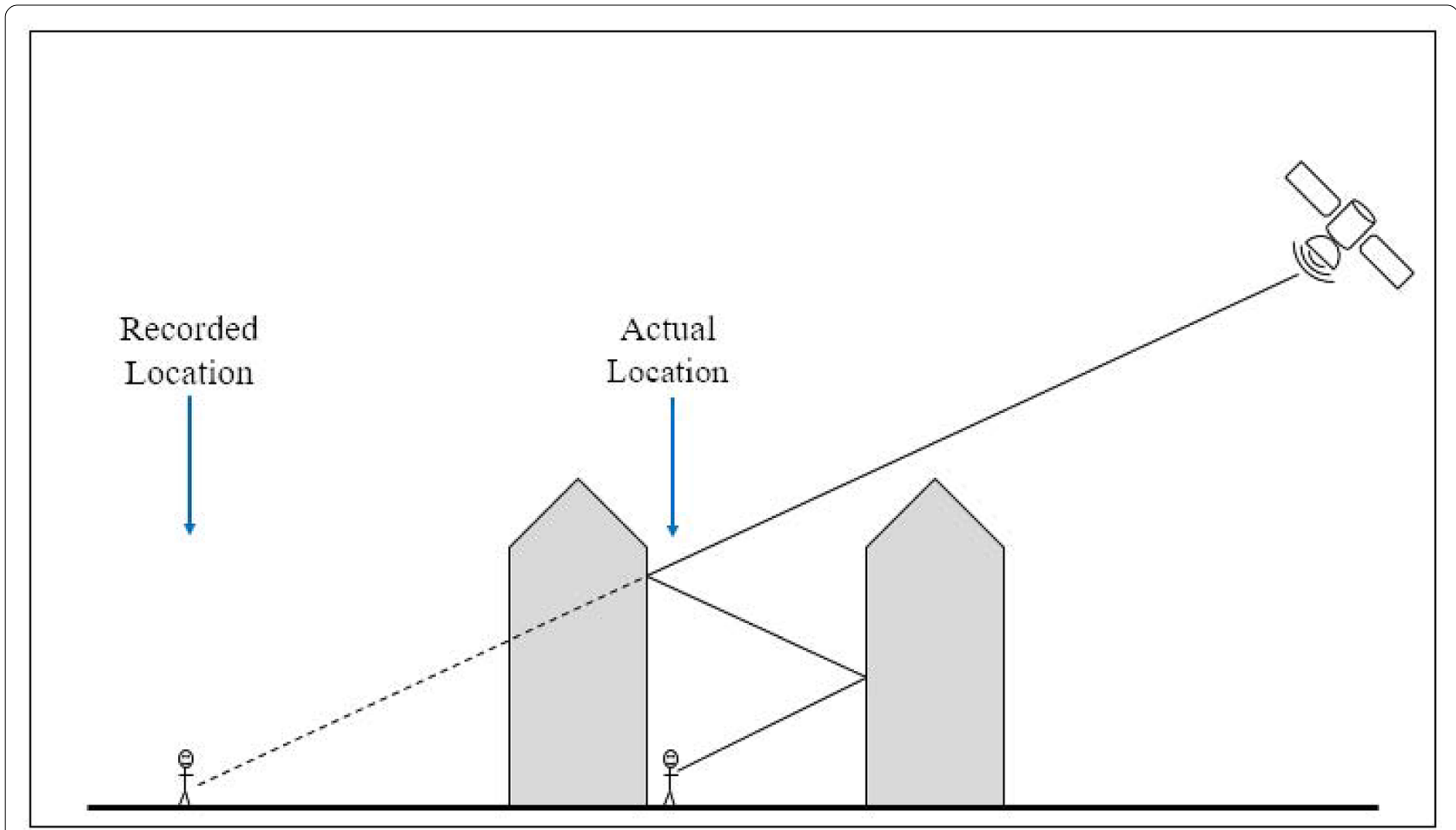

Fig. 1 The urban canyon effect Perceived locations differ from actual locations due to GPS signals reflecting off of tall buildings

With this in mind, it is important to consider the tools and expertise that practitioners and researchers might have at their disposal. This analysis is in no way trying to improve on the sophisticated and proprietary algorithms used by companies such as Google, Microsoft, Uber, or CityMapper-companies that have all invested heavily in mapping systems which can take raw GPS tracking data and interpolate an individual's path through the urban network, determine their likely mode of transport, and account for other factors such as traffic conditions, environmental factors, and potentially more accurate path data from other users of their services. These companies also have a broader range of tools with which to measure movement. These include: multilateration (measuring the time that energy waves sent from a mobile phone take to reach different network towers in the area); mobile phone signal strength measured from several network cell towers; crowd-sourced WiFi data from nearby receivers; and a much more extensive dataset of pedestrian movement.

Instead, this paper focusses on how accurately police patrol dosage can be estimated, particularly from the viewpoint of a police analyst or academic researcher who might have access to GPS data from officer-worn radios. The number of studies that have already utilised GPS data in the measurement of police dosage is small as the technology is relatively new in law enforcement and thus evaluations have only recently been able to utilise
GPS data to measure patrols. Some have counted the number of GPS pings within patrol locations and then multiplied that by the (standard) time between pings. For example, the experiment by Ariel et al. (2016) used GPS data where the location was recorded every minute. If, for instance, three pings occurred within a patrol box, they would count this as $3 \mathrm{~min}$ of dosage. Alternatively, a 'join-the-dots' approach has been used, whereby an officers path was assumed to be a straight line between GPS pings and that they moved at a constant speed between pings. When one ping falls outside a patrol location and the next ping falls inside the patrol location, the entry time can be calculated accordingly (Hutt et al. 2018).

For both these strategies, the frequency with which pings occur, and where along an officer's path they occur may have a significant impact on where dosage is assigned. The next section outlines the first experiment and confirms that GPS data can be used as reliable measure of where officers were at the time. This is followed by the second experiment, conducted with the MPS in London to measure how different GPS data refresh rates affect the interpolated paths officers have been estimated to have taken. The paper concludes with a discussion of the findings and their implications for future evaluations of micro-place policing interventions. 


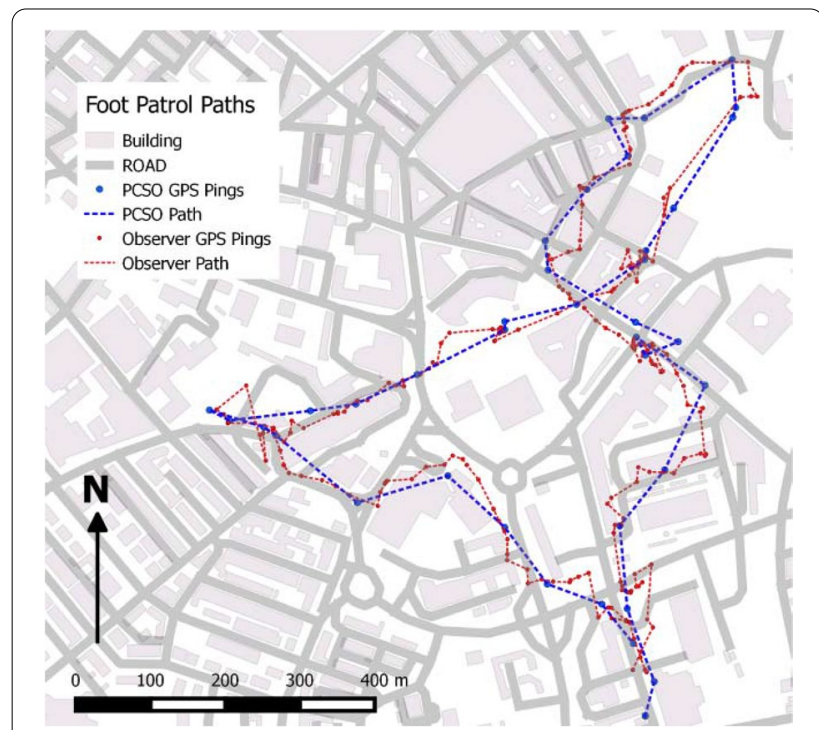

Fig. 2 GPS pings within a city centre

\section{Experiment 1: Comparing police GPS data against a known path}

A preliminary experiment was conducted in conjunction with a police force in the North of England to assess the accuracy of GPS data collected via officer-worn radios. The main objective was to establish whether the officer GPS data accurately reflect where the officer actually was. The researcher accompanied officers on foot patrols in two areas-one more suburban and a city centreover 2 consecutive days recording the author's location approximately every 15 to $20 \mathrm{~s}$ using a smartphone-based GPS recording application. Notes were made during the patrols of the exact paths taken and these, along with the researcher's recollection of the paths, were used to verify the accuracy of the smartphone data. A very small number of smartphone data points were incorrect and these were removed from the analysis so that the true paths were accurately specified. GPS data collected from officer radios every $2 \mathrm{~min}$ was then provided by the police force for the officers that had been accompanied. Figure 2 shows the officer ${ }^{2}$ and researcher GPS pings for the city centre patrol. For ease of interpretation, the figure shows an interpolated path between successive GPS pings as a direct line between them.

Each officer GPS ping was matched to the researcher ping that occurred nearest in time so that the spatial distance between them could be measured. A total of 41 matched pairs were recorded in the residential area

\footnotetext{
${ }^{2}$ In this instance the officer was a Police Community Support Officer (PCSO).
}

and 30 matched pairs recorded in the city centre with median distances between matched pings of $15.3 \mathrm{~m}$ and $18.4 \mathrm{~m}$ respectively. To account for the fact that the researcher and officers were moving, only pairs of pings that occurred within $15 \mathrm{~s}$ of each other are included, with the median time between matched pings being $7 \mathrm{~s}$ for both groups. It was expected that there would be some distance between the matched pairs for several reasons. First, the average pedestrian walking speed is $1-1.4 \mathrm{~m} / \mathrm{s}$ (Levine and Norenzayan 1999; Snaterse et al. 2011) and so if the matched pings do not occur at exactly the same time there will be some distance between them even if spatial measurement were perfect. Second, the GPS receivers were not being held by the same individual and so again, even if all other measurements were perfectly accurate there would be an expected distance of several metres between matched pings. And finally, there is a measurement error associated with the devices being used to record both the officer and researcher locations. On this final point, the GPS receivers in the officer radios have a Circular Error Probability of $5 \mathrm{~m}$ meaning that for $50 \%$ of GPS pings the true location is within $5 \mathrm{~m}$ of the reported location ( $95 \%$ within $10 \mathrm{~m})$. A study of smart phone positional accuracy by Merry and Bettinger (2019) found that the error in an urban environment was in the range of 7 to $11 \mathrm{~m}$ for an environment similar to that of this study. Thus taking these three measurement uncertainties together it should be expected that there is some distance between the matched ping pairs. The distributions of the matched pair distances are shown in Fig. 3. These results do not assess the exact measurement error of the GPS receivers used by the officers; that would have required measuring the exact location of an officer and comparing it to a GPS ping recorded when they were stationary in that location. However, these results do provide some reassurance that the data is not wildly inaccurate, (at least in the majority of cases) and can broadly represent the paths officers have taken.

An important auxiliary finding was made from this experiment: there are times when officers are not traversing known roads or paths. On both patrols there were instances of officers traversing areas which on a map would appear to have no clear through-way, whether they be unmapped paths between streets, across parks, or through other public spaces. A similar pattern was discovered later whilst conducting patrols with officers in London; there were several occasions when the officers path diverges from roads and pavements as they make their way through housing estates and other non-standard walkways. These paths often meander as officers try to cover the area of their patrol, which highlights another disparity with standard movement-the objective of the patrol is not to get from one point to another as quickly 


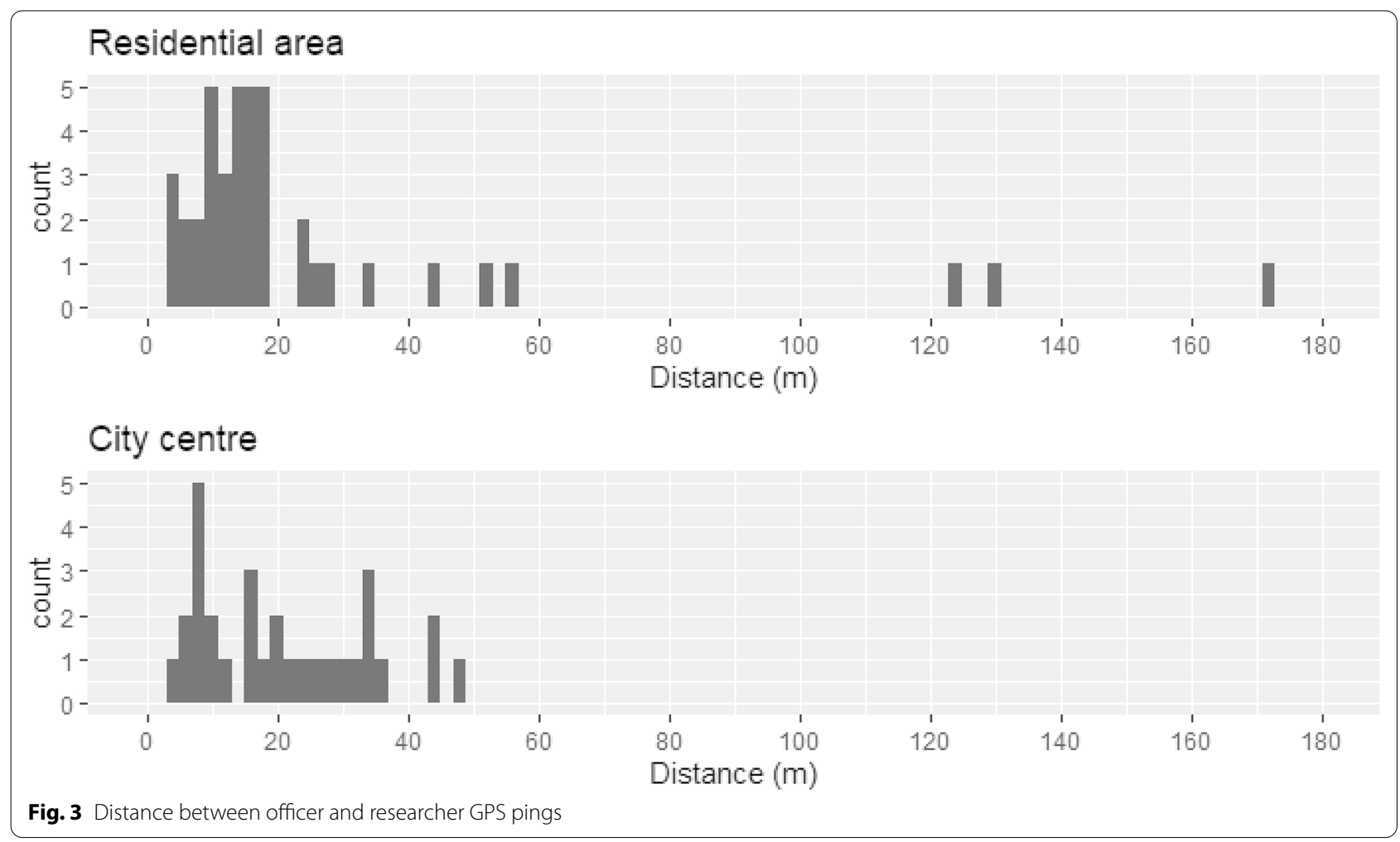

as possible; it is to cover an area and as such officers do not always take the most direct paths between two points on their route.

These phenomena highlight an important issue in trying to accurately map foot-patrol paths; attempting to 'correct' GPS paths by matching them to known road and path structures (a process known as map matching) may in fact add errors, particularly as most map-matching algorithms assume a certain efficiency of path finding between points. Foot patrols, unlike vehicle patrols, are not constrained by the 'official' path that exists nor by the standard desire to get between points as efficiently as possible.

Building on these insights, the next experiment was conducted in a densely populated area of Southern England and was designed to measure how the paths interpolated from GPS data differ when using data collected at different rates. Whilst it was not feasible to systematically record the true path that officers took, the purpose of the experiment was to evaluate whether different GPS ping rates would lead to significantly different patrol paths being assumed.

\footnotetext{
${ }^{3}$ The original intention was for the radios to transmit locations every $10 \mathrm{~s}$, but this was not feasible due to limits within the recording infrastructure.
}

\section{Experiment 2: The effect of GPS refresh rate on interpolated officer paths}

In 2017, approximately 40 police officers from the MPS agreed to wear a secondary radio whilst out on foot patrol. These radios transmitted the officer's location every $30 \mathrm{~s}^{3}$-a significantly faster refresh rate than the 5 min interval used for standard MPS body-worn radios. The purpose of this more frequent refresh rate was to allow for foot patrol paths to be measured at a higher resolution. Due in part to radio malfunction, a total of 31 officers ultimately participated in the experiment and recorded 214,342 'location pings' using the secondary radios. This equates to approximately $1786 \mathrm{~h}$ of recording or $2238 \mathrm{~h}$ police shifts ranging from the 8th November 2017 to the 16th January 2018. Figure 4 shows the distribution of the data over the study period and that over time officers were less likely to carry their secondary radio (or potentially that the radios developed technical issues), particularly after the Christmas break. All the data have been included in the analyses that follow.

A notable feature of the data is that they were not just recorded when officers were conducting patrols. For this reason, the data have been cleaned so that only data relating to actual foot patrols were used for the analysis; removing, for instance, time spent in police stations or travelling either in police vehicles or on public transport. Whether an officer's movements 


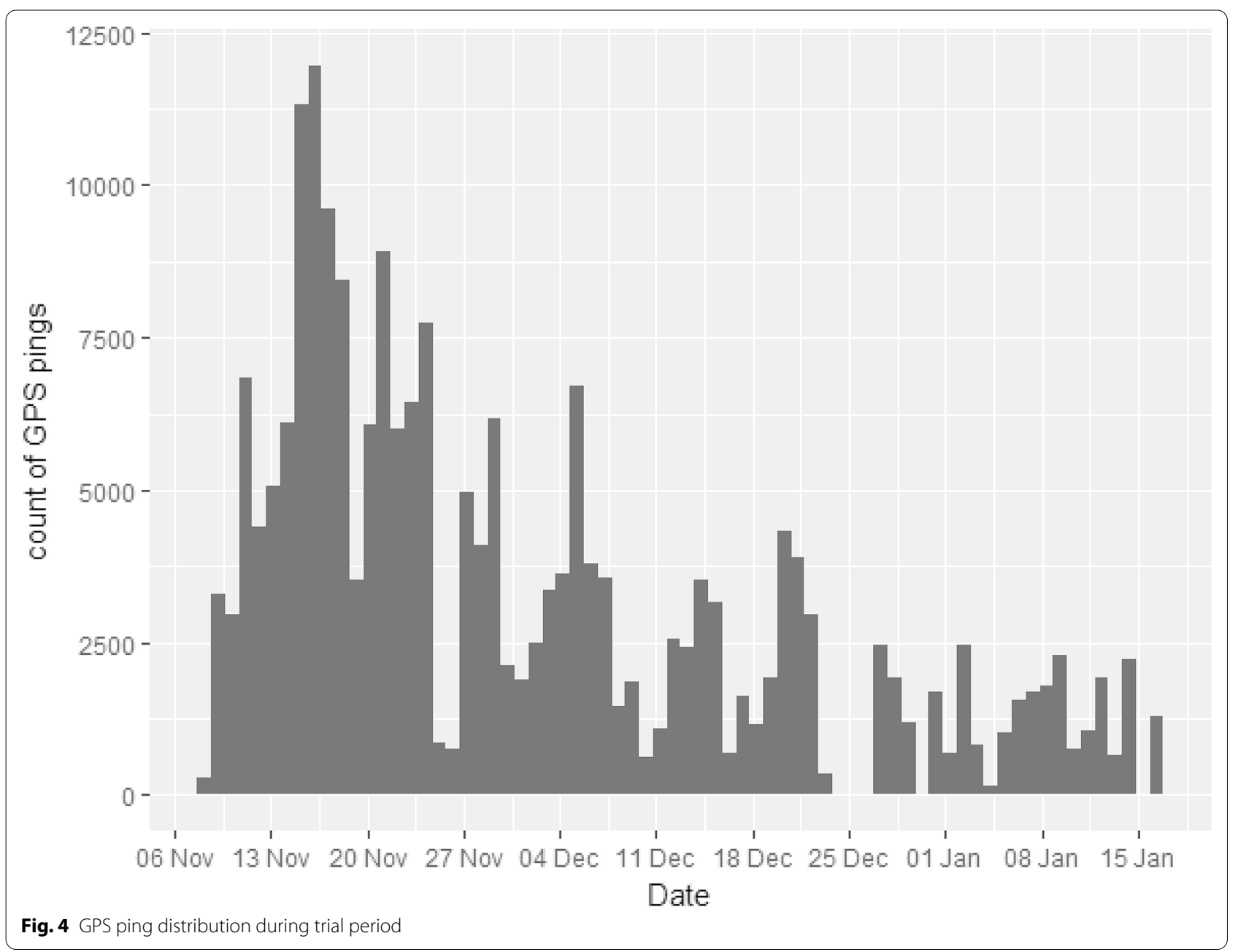

were on foot or by vehicle was determined by calculating the average speed between GPS pings and discounting any travel at more than $2 \mathrm{~m} / \mathrm{s}$. As discussed above, the standard pedestrian walking speed is 1 to $1.4 \mathrm{~m} / \mathrm{s}$. Given that police officers are carrying a considerable extra weight in the form of their vests and equipment it was assumed that they would not be walking any faster than a standard pedestrian when they are on foot patrol. This also had the effect of removing some of the more extreme cases of the urban canyon effectwhereby an officer would suddenly appear several $100 \mathrm{~m}$ away from their previous ping location just 30 $s$ previous. In other words, by removing the GPS data which implies the officers were walking improbably fast the remaining data more accurately reflect the 'ground truth' of patrol routes.

Officer paths were interpolated based on the $30 \mathrm{~s}$ refresh rate GPS data, to create a baseline 'assumed path'. Prior to Experiment 1 (above) being conducted, it was anticipated that a map-matching algorithm would be used to try and accurately interpolate officer paths in this experiment. However, given the observation that officers were not always constrained to known pathways, this was discarded and the method of interpolation used was a simple 'as the crow flies' direct line between consecutive GPS pings. Subsets of the GPS data are then created such that paths are interpolated based on 60, 90, 120 (and so on) second intervals up to 5 min intervals.

There are many ways of measuring the similarity of two paths. Magdy et al. (2015) provide a useful review, separating the methods into Spatial and Spatio-temporal similarity measures. The spatio-temporal methods can immediately be discounted for the present analysis. The paths we wish to compare (30 s ping rates versus more sparse ping rates) are derived from the same dataset and thus any temporal analysis is not sensible. Of the spatial similarity measures, the Fréchet metric (or distance) is the most popular similarity measure in use according to Gudmundsson et al. (2011) and its use here is also appropriate. 


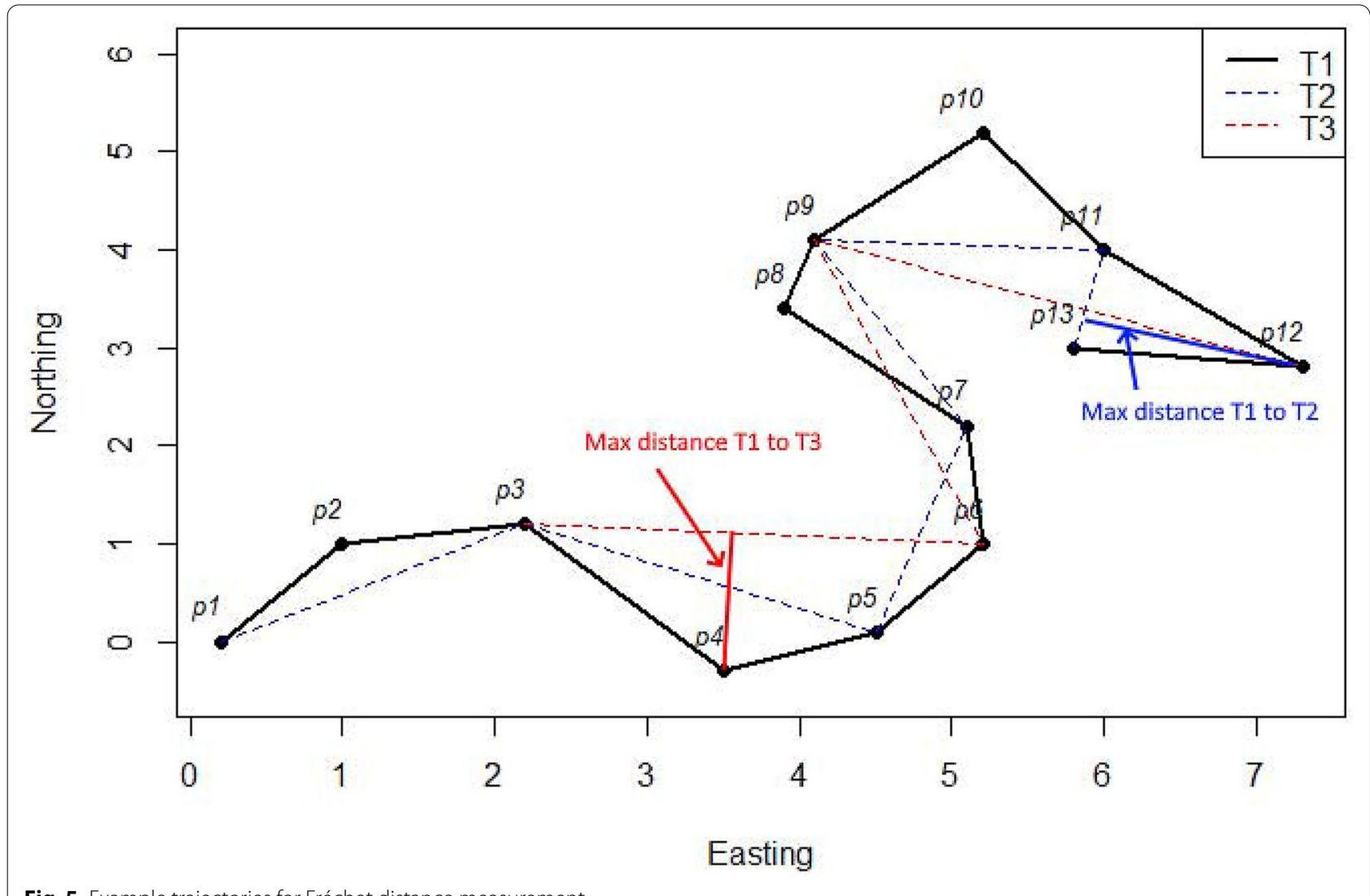

Fig. 5 Example trajectories for Fréchet distance measurement

The Fréchet distance can be described as follows. Assume we have two paths, $A$ and $B$. At the start of path $A$ there is a dog and at the start of path $B$ the dog's owner. Both the owner and the dog can walk along their respective paths and they can each vary their speed, though they can not move backwards. The Fréchet distance is the minimum length of leash that would be necessary to connect the dog and its owner for the entire journey from the start to the end of their respective paths. Alternatively, consider the path $A$ as being made up of infinitely many points. For each point, calculate the shortest distance to path $B$. The Fréchet distance is the maximum of all these shortest distances. It is important to note that for our data, the distances are not only calculated where the GPS pings occur, but along the entire path. These paths are also often referred to as trajectories.

As one of the trajectories being compared in this analysis is created from a subset of points from the other, (e.g. the $60 \mathrm{~s}$ trajectory points are a subset of the $30 \mathrm{~s}$ points) there will of course be regular intervals where the trajectories 'touch'. However, this is not an issue as the Fréchet distance is the minimum leash length over the entire trajectory. That said, in measuring the similarity of two trajectories, using the Fréchet distance over the full patrol would provide very little useful information as it would only provide us with the maximum distance between the trajectories. The analysis would be highly susceptible to noise within the data such as erroneous pings caused by urban canyon effects.

To account for this, instead of computing the Fréchet distance for the entire path, it is segmented into multiple path sub-patrols, defined as the shortest sequence of consecutive GPS pings in each trajectory which share a common start and end ping. The Fréchet distance is then calculated for each sub-patrol. This provides a distribution for the similarity between the two trajectories. As a basic example, Fig. 5 shows a set of points in black which might represent a patrol officer's GPS pings starting from the location $(0.2,0)$. Let us imagine that these pings occur every $30 \mathrm{~s}$ and label them $p_{1}, p_{2}, p_{3}, p_{4}$ etc. Three trajectories have been created:

- $T_{1}$ : based on taking every ping and interpolating the 'assumed path' (the solid black line) as the route taken by walking in a straight line between each ping.

- $T_{2}$ : an interpolated path constructed by using every other ping $p_{1}, p_{3}, p_{5}, p_{7} \ldots$ (the dashed blue line). This 


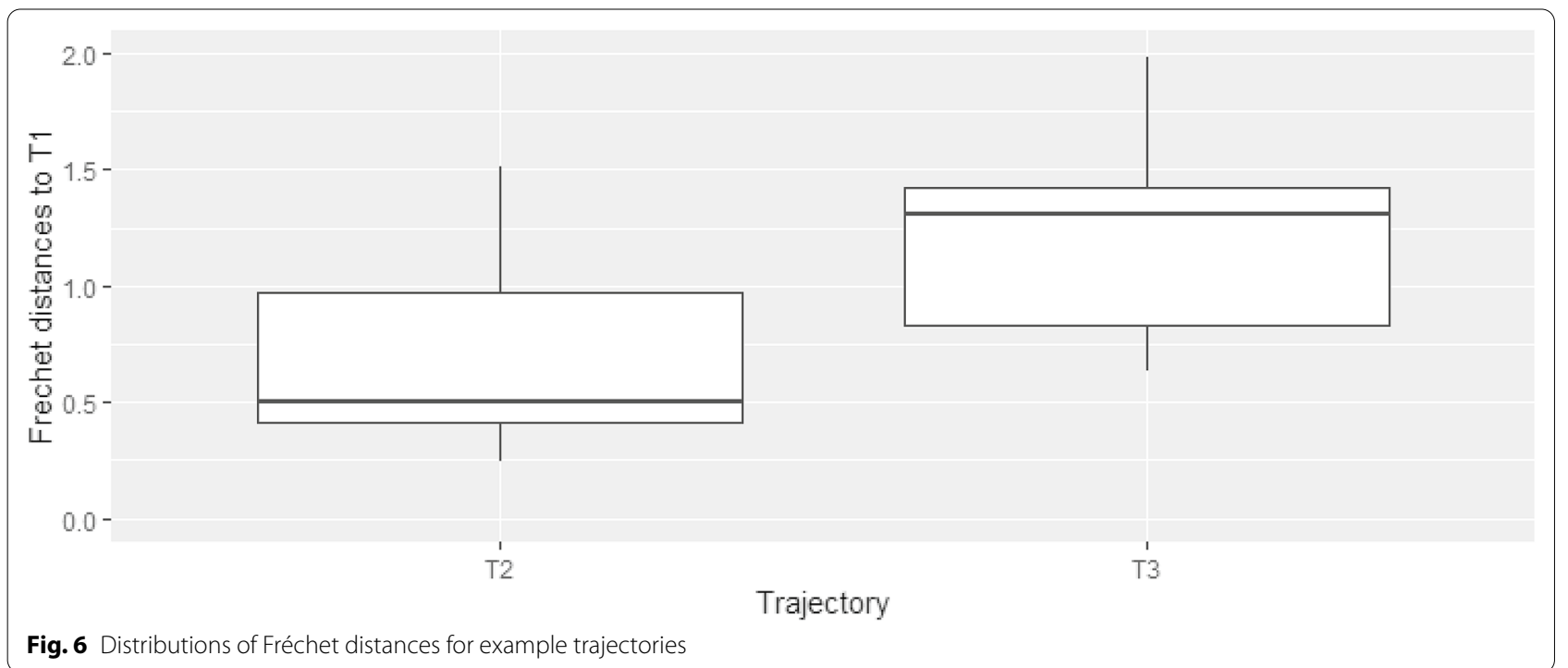

would be a potential interpolated path if GPS pings were recorded every $60 \mathrm{~s}$ rather than every $30 \mathrm{~s}$.

- $T_{3}$ : an interpolated path constructed by using every third ping (dashed red line). Note that the paths need not all start from the same point and so this trajectory is formed of $p_{3}, p_{6}, p_{9}, p_{12} \ldots$; the important distinction is the frequency with which the points are used in the interpolation-i.e. this represents a $90 \mathrm{~s}$ ping refresh rate. There are two alternative interpolations that use a $90 \mathrm{~s}$ GPS ping rate-one which starts at $p_{1}$ and one which starts at $p_{2}$.

The sub-patrols for $T_{1}$ and $T_{2}$ are defined by $\left\{p_{1}, p_{2}, p_{3}\right\}$, $\left\{p_{2}, p_{3}, p_{4}\right\},\left\{p_{3}, p_{4}, p_{5}\right\}$, etc. and the sub-patrols for $T_{1}$ and $T_{3}$ are defined by $\left\{p_{1}, p_{2}, p_{3}, p_{4}\right\},\left\{p_{2}, p_{3}, p_{4}, p_{5}\right\}$, $\left\{p_{3}, p_{4}, p_{5}, p_{6}\right\}$, etc. The maximum Fréchet distance between $T_{1}$ and both the $60 \mathrm{~s}$ ping-rate possibilities [i.e. using every odd ping $\left(T_{2}\right.$ ] or every even ping (not shown)) is approximately 1.5 and is highlighted on Fig. 5. Whilst the Fréchet distance between $T_{1}$ and $90 \mathrm{~s}$ ping rate possibilities (exemplified by $T_{3}$ ) is 1.98 and is again shown on Fig. 5. Rather than use just this single number, the Fréchet distance is computed for each sub-patrol as defined above. This provides a distribution of how similar the trajectories are by evaluating sections of the trajectories. Given the very simple (and low sample count) example provided, the distributions for this example are given as boxplots in Fig. 6.

The basis of the main experiment on police trajectories is to compare more sparse GPS data against an assumed path using a $30 \mathrm{~s}$ ping rate and thus it is important that the assumed path being used as a baseline does in fact contain a GPS ping every $30 \mathrm{~s}$. As such a second phase of data cleaning was required. Data for each officer were split into 'sub-patrols' by selecting sequences of pings that occurred within $40 \mathrm{~s}$ of each other and where the maximum distance between two pings was $150 \mathrm{~m}$. A threshold of $40 \mathrm{~s}$ was allowed as the radios did not always ping exactly every $30 \mathrm{~s}$, perhaps due to delays in the data being received. This produced 22,951 'sub-patrols'. Any sub-patrol with only one or two GPS pings was removed and after inspection of the data, any sub-patrol with more than 60 GPS pings (i.e. more than 15 min of persistent 30 -s pings) were also removed. This reduced the number of subpatrols to 10,925. The long un-interrupted patrols were found to be due to a radio being switched on and left in one place for an extended period of time or because an officer was stationary. For instance, if an officer was at a hospital or school. The purpose of the data collection was to measure actual patrol movements and so removing these 'stationary periods' is not a concern. Similarly, if during a sub-patrol an officer did not move on average $0.3 \mathrm{~m} / \mathrm{s}$ the patrol was discarded due to the officer being mainly stationary. This left a final sample of 6064 sub-patrols to use for the analysis. The median number of GPS pings in a sub-patrol was 8.98 and the inter-quartile range was 4 to 11 . One such sub-patrol is given in Fig. 7 with examples of potential paths interpolated using different ping refresh rates. It is interesting to observe that there is quite some variation in the routes, particularly between the $30 \mathrm{~s}$ and 5 min ping rate paths. 


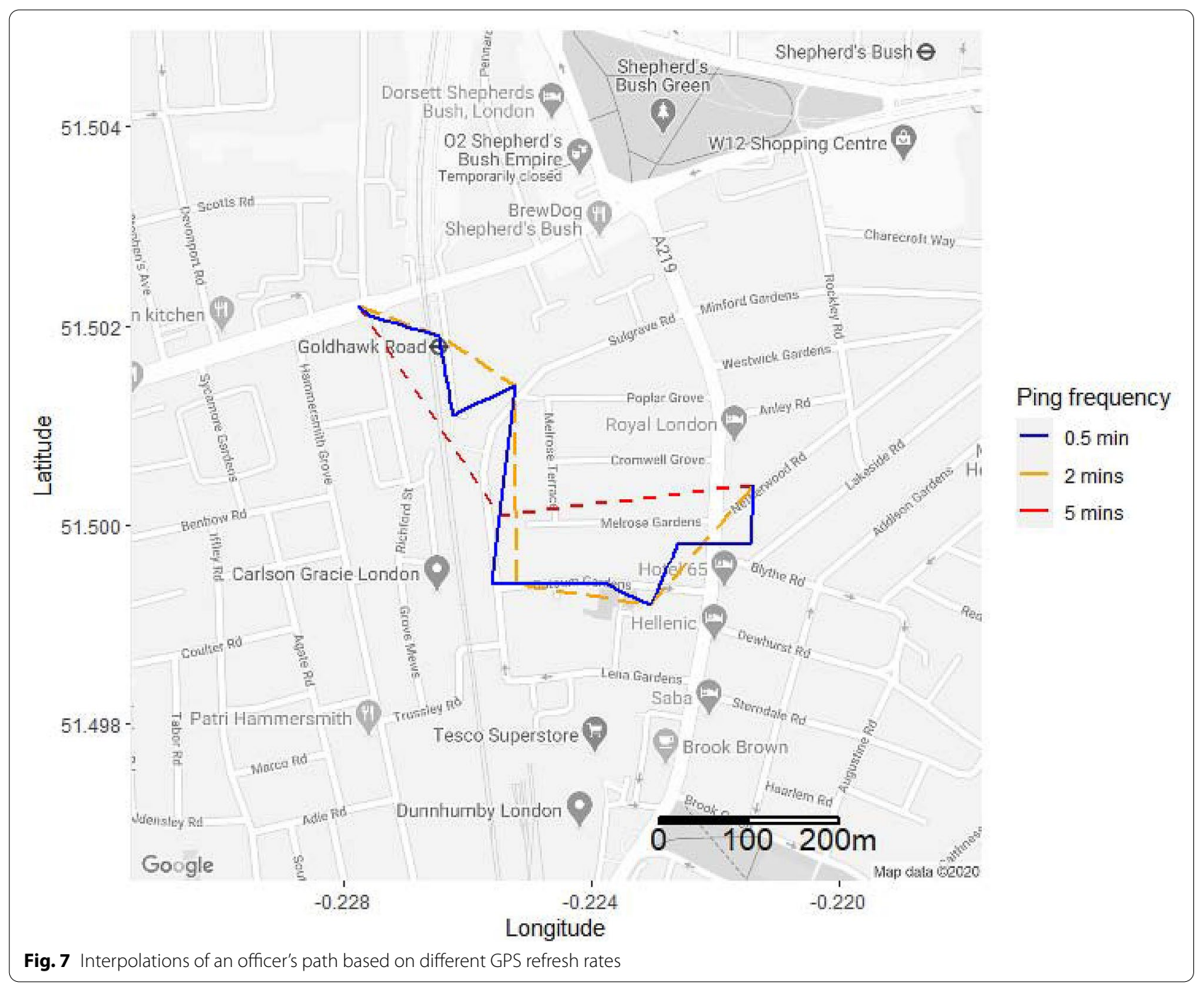

It is also worth highlighting that in this particular example, the roads and walkways that an observer might assume the officer walked are likely to differ between the $30 \mathrm{~s}$ and $5 \mathrm{~min}$ refresh rates, and this is an important issue to consider given the increasing use of road-segments as the unit of analysis both for defining crime risk (Rosser et al. 2017; Tompson et al. 2009) and for analysing patrol routes (Davies and Bowers 2019).

\section{Experiment 2: Results}

The Fréchet distances were calculated between officer patrol paths using $30 \mathrm{~s}$ GPS ping rates (the officer's assumed path) and more sparse data sampled from this same dataset-hence the data shown for each ping rate represents a comparison against the $30 \mathrm{~s}$ ping rate as a 'baseline' and describes the distance between the path for the given ping rate when compared against the path using the assumed true path-the $30 \mathrm{~s}$ ping rate. The distributions of these distances are shown in Fig. 8. The similarity of the patrol paths reduces as the assumed path is interpolated based on sparser data. A $60 \mathrm{~s}$ ping rate provides a very similar path to that produced by a $30 \mathrm{~s}$ ping rate and although there is a long tail to the distribution the median distance between paths using $30 \mathrm{~s}$ ping rates and paths using $60 \mathrm{~s}$ ping rates is $0 \mathrm{~m}$. However, less frequent refresh rates quickly lead to dissimilar paths: the median Fréchet distance when comparing a path using 30 $\mathrm{s}$ ping rates to a path using $5 \mathrm{~min}$ ping rates-the standard for MPS radios-was $60.1 \mathrm{~m}$ and again, there is a long tail to the distribution. Table 1 provides some basic descriptive statistics of the distributions. It illustrates that the decrease in accuracy is non-linear. That is, accuracy decreases rapidly (for refresh rates of 90, 120 and $150 \mathrm{~s}$ ) but then declines much less quickly.

Whilst an median divergence of about $60 \mathrm{~m}$ between the $30 \mathrm{~s}$ and $5 \mathrm{~min}$ ping rates does not seem great 


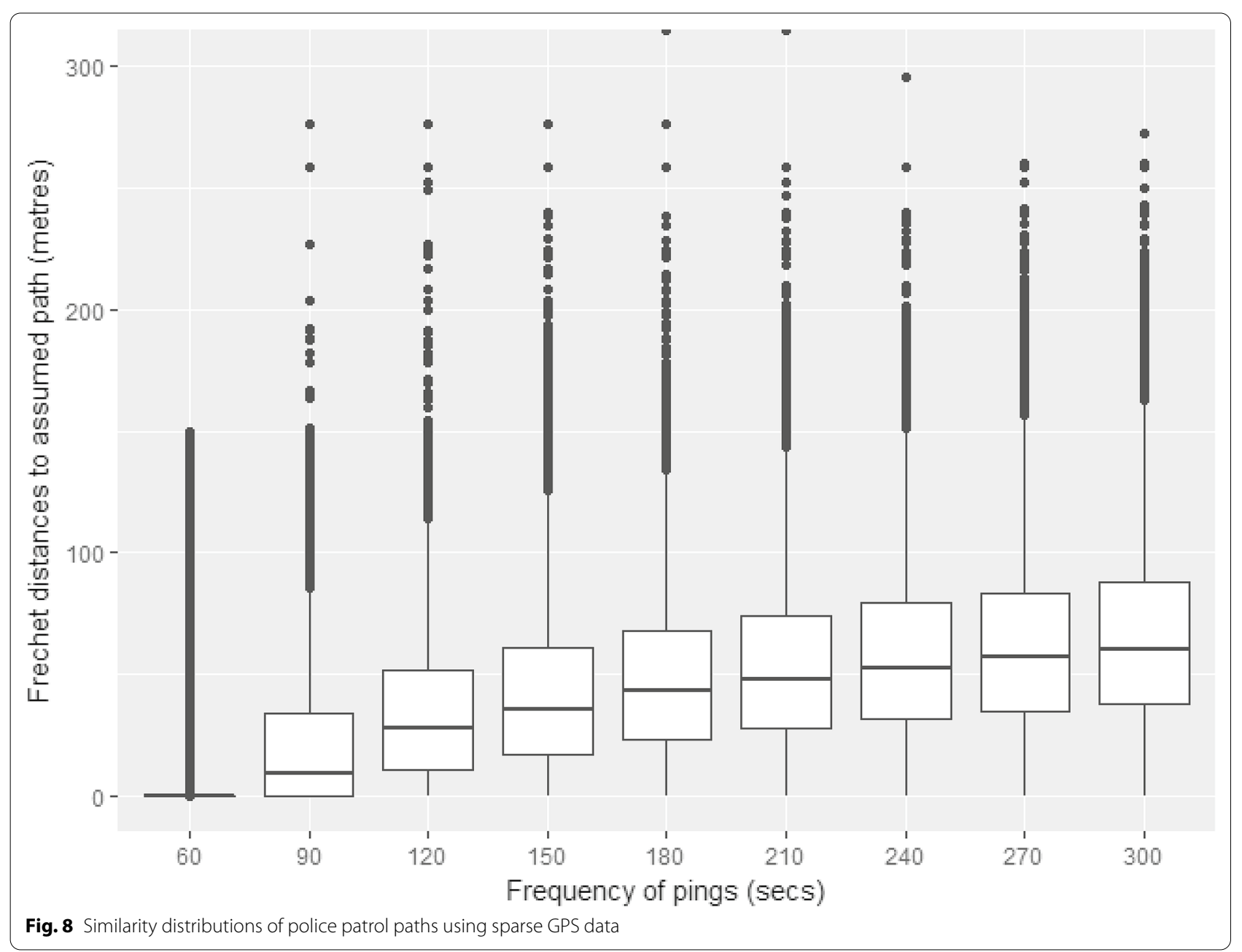

Table 1 Distribution of Fréchet distances by ping frequency

\begin{tabular}{lllll}
\hline $\begin{array}{l}\text { Ping } \\
\text { frequency }(\mathbf{s})\end{array}$ & \multicolumn{4}{l}{ Fréchet distance $(\mathbf{m})$} \\
\cline { 2 - 5 } & 1st quartile & Median & Mean & 3rd quartile \\
\hline 60 & 0 & 0 & 6.81 & 0 \\
90 & 0 & 9.32 & 21.67 & 34.25 \\
120 & 10.47 & 27.85 & 34.94 & 51.97 \\
150 & 17.09 & 35.80 & 41.81 & 60.54 \\
180 & 23.21 & 42.80 & 47.85 & 67.72 \\
210 & 27.31 & 47.85 & 52.64 & 73.75 \\
240 & 31.24 & 52.68 & 57.24 & 79.16 \\
270 & 34.74 & 56.65 & 61.21 & 83.49 \\
300 & 38.00 & 60.07 & 64.92 & 87.78 \\
\hline
\end{tabular}

(approximately two thirds of the length of a Premier League football pitch), it is important to highlight the spatial resolution at which police patrols are now being measured. With hot-spots of crime being defined in the tens or hundreds of metres, these data uncertainties could begin to have a significant effect on the perceived efficacy of police patrols and on the utility of the more sophisticated crime prediction systems being developed. Indeed, some predictive crime mapping systems (such as PredPol) define hot-spots that are roughly $150 \mathrm{~m}$ across; meaning that a $60 \mathrm{~m}$ average error could be the difference between an officer appearing near the centre of the hotspot or outside it entirely.

\section{Conclusions}

The intention of this paper was to explore the potential impact of measurement error in the use of GPS data to measure police foot-patrol. The advent and wider availability of GPS technologies to measure movement offer new opportunities to develop better evidence to support policing. However, the use of GPS data in analysis should not just assume that this reflects the true picture of policing activity. A useful conclusion would identify minimum 
acceptable standards in terms of GPS ping rate when it comes to accurately representing patrolling locations.

If we ignore for a moment the additional costs associated with more frequent ping rates and only consider the accuracy of the path in order define the 'best' ping rate, then a 60 or $90 \mathrm{~s}$ rate provides very little deviation from a $30 \mathrm{~s}$ ping rate and so in an ideal world this might be the suggested optimal rate (when measuring officer movements in micro-places). However, practical considerations make defining what is 'best' unwise at such a general level. As mentioned earlier, there are substantial additional costs associated with increased ping rates: the battery in the officer's radio will deplete at a faster rate, shortening both the time between charges (and thus the time officers can be on patrol) and the overall life of the battery through more frequent charges. The latter amounts to a substantial financial burden if a police force is made to replace all officer radios more frequently. More frequent ping rates also require greater data storage capacity for the organisation to keep the same period's worth of data; the cost of a force's radio contract is also contingent on the frequency of pings as more frequent data collection has greater overheads for the service provider. Finally, more frequent pings afford a greater volume of data to analyse, increasing computational need for the analyst or system displaying that data. A secondary consideration is what the data are being used for. If a police force has no need to measure officer movement at such granularity, or if there are very few areas with dense urban street networks, then a more sparse ping rate may suffice for their needs. For these reasons it is unwise to state what the 'best' ping rate is; it will be different for each police force and only they have a true understanding of their needs.

It is important to note that the analysis presented in this paper, and the previous studies which used GPS data discussed earlier are concerned with foot-based police patrols, which are used in the UK to conduct preventative patrols-particularly in crime hot-spots (College of Policing 2012). This paper has not sought to evaluate these paths against hot-spots for two reasons. First, the officer's involved in this study were conducting foot patrols, but the focus of where they were supposed to be patrolling and what they were trying to achieve when in those areas were not known; it would be inappropriate to try and measure their impact on local crime issues

\footnotetext{
${ }^{4}$ It should be noted that the officers who took part in this experiment covered several different teams with different responsibilities, so whilst they were all engaged in foot patrols, each team may have had different priorities and due to the anonymisation of the data before it was passed to the researcher there would be no way to assign each patrol to a particular objective.
}

without being sure which issues they were trying to address. ${ }^{4}$ Second, the measurement of police dosage in a given area requires a clear definition of the spatial and temporal units of analysis-i.e. over what area and what time period should dosage be measured? Such analyses are certainly necessary and worthy of future study, but they were beyond the scope of this experiment.

To summarise, assumed officer patrol paths were interpolated using GPS data collected with a $30 \mathrm{~s}$ refresh rate. The similarity of these paths to paths based on increasingly sparse data were compared to evaluate how the frequency of data collection affects the path an officer is assumed to have taken. Police forces in the UK are known to use GPS refresh rates of between 2 and $5 \mathrm{~min}$ and so based on the results of this study they would produce assumed paths which, at any given point, deviate from these more regularly measured paths by a median distance of 28 to $60 \mathrm{~m}$. Whilst this distance may seem relatively small it is only an average path deviation and when the sum total of patrol officer paths is considered it may lead to substantially different estimates of patrol dosage. This is particularly the case when analysis is conducted at small spatial resolutions-increasingly the standard when both defining and evaluating hot-spot policing strategies.

What this analysis highlights is that evaluations of predictive crime mapping systems in particular must pay attention to the accuracy of the data being used. As discussed in the introduction, some evaluations do now note the issue of data inaccuracy but the authors are unaware of any study to date which has investigated the size of the potential errors caused by the measurement uncertainty. This is not to say that past evaluations have been wrong or insufficiently robust, only that the exact magnitude of any evaluated effects of patrol at micro-places need to be properly considered. For police forces that are considering implementing or procuring micro-level hot-spotting systems, their is a clear need to demonstrate that the system they intend to use is firstly, better than any alternative systems (by accurately measuring the difference) and secondly, a better use of resources than a separate project entirely. The implication of this paper then is that more sparse ping rates may substantially alter the evaluated impact of patrol by mis-recording patrol intensity in micro-places which in turn could impact what intervention is deployed. From a more bureaucratic viewpoint, it is also important to ensure that any system not procured is unable to challenge the results due to measurement uncertainty. Shorter ping refresh rates can thus reduce the chances of such challenges being mounted and provide a more robust defence against challenges.

Several limitations exist within the analysis described here. The true paths walked by the officers is unknown. The GPS data still only approximates the officers' 
locations; their path between pings has been interpolated and measurement error still exists within the collection of GPS data. Urban canyon effects can significantly distort the estimated location of an officer although concerns over these issues have been somewhat mitigated by the first experiment with the northern police force which showed that GPS data did provide a relatively accurate representation of the true path taken. Also, an attempt was made to mitigate some of these issues by removing 'noisy' data-where the distance between pings was unrealistically far or the speed travelled between pings too great for the movement to have been by foot. As such, only trajectories which could confidently be classified as realistic patrol routes were analysed.

The use of GPS data to estimate police patrol dosage is a relatively new development. So far, very few studies (Ariel et al. 2016; Hutt et al. 2018; Williams and Coupe 2017) have used GPS data to try and measure the deterrent effect of police patrols and to the authors' knowledge this is the first to examine the similarity of police patrol paths using GPS data. However, as patrols have become more targeted the impact of the accuracy of the measurement of police patrols requires greater consideration. GPS data do not provide a perfect solution to the challenges of measurement, however they have several advantages over the methods previously used. This includes greatly reduced manual effort to record the necessary data. GPS data are already being recorded in order to be able to locate officers when necessary and so using the same data for patrol estimation requires no additional expenditure. The passive nature of the data collection also provides flexibility in the analysis. As the data are not reliant on officers remembering to record a state change at a given point (such as entering or exiting a hot-spot) if the parameters of the measurement change (for example, if officers were told to patrol certain streets rather than specific areas or if the size of the hot-spots is altered) then the data is still valid as it provides a history of the officer's movement rather than just entry and exit from a fixed area.

With a growing number of commercial micro-place hot-spot systems emerging it is important for police forces to be able to accurately evaluate implementations of such systems. Robust comparisons between such systems need to be feasible in order for police management to determine where their resources can be most efficiently used and thus the accuracy with which police patrols are measured needs to be clearly stated in any evaluation if practitioners are to have confidence in the results.
Abbreviations

AVL: Automated Vehicle Locator; GPS: Global Positioning System; MPS: Metropolitan Police Service.

\section{Acknowledgements}

The authors wish to thank the police forces involved and particularly the Metropolitan Police Service for their support in collecting the data used in this research. This work is supported by the Engineering and Physical Sciences Research Council (EPSRC), grant number EP/M506448/1.

\section{Authors' contributions}

This work formed part of a $\mathrm{PhD}$ thesis submitted by $\mathrm{OH}$ and supervised by $\mathrm{KB}$ and SJ. The overall study design, data collection, and analysis was conducted or instigated by $\mathrm{OH}$ with contributions from KB and SJ. SJ proposed and facilitated the data collection for Experiment 1. OH led the writing with contributions from all authors. All authors read and approved the final manuscript.

\section{Availability of data and materials}

The data used in this research (consisting of police recorded crime data and officer GPS data) cannot be publicly shared.

\section{Competing interests}

The authors declare that they have no competing interests.

Received: 16 July 2020 Accepted: 11 January 2021

Published online: 05 February 2021

\section{References}

Andresen, M. A., \& Hodgkinson, T. K. (2018). Evaluating the impact of police foot patrol at the micro-geographic level. Policing: An International Journal,41(3), 314-324.

Ariel, B., Weinborn, C., \& Sherman, L. W. (2016). 'Soft' policing at hot spots-do police community support officers work? A randomized controlled trial. Journal of Experimental Criminology. https://doi.org/10.1007/s1129 2-016-9260-4

Bowers, K., Johnson, S. D., \& Hirschfield, A. (2004). The measurement of crime prevention intensity and its impact on levels of crime. British Journal of Criminology,44(3), 419-440. https://doi.org/10.1093/bjc/azh020.

Braga, A. A., Turchan, B., Papachristos, A. V., \& Hureau, D. M. (2019). Hot spots policing of small geographic areas effects on crime. Campbell Systematic Reviews, 15(3), 1046

College of Policing. (2012). What works in policing to reduce crime-The effectiveness of visible police patrol. Technical report, College of Policing . https ://whatworks.college.police.uk/Research/overview/Pages/more.aspx.

Davies, T., \& Bowers, K. (2019). Patterns in the supply and demand of urban policing at the street segment level. Policing and Society,30(7), 1-23.

Gudmundsson, J., Laube, P., \& Wolle, T. (2011). Computational movement analysis. Springer handbook of geographic information (pp. 423-438). Berlin: Springer.

He, Z., Hu, Y., Wu, J., Wang, J., Hou, J., \& Wang, K. (2011). A comprehensive method for multipath performance analysis of GNSS navigation signals. In 2011 IEEE international conference on signal processing, communications and computing (ICSPCC) (pp. 1-6). New York: IEEE.

Houda, P. (2016). Performance of map matching and route tracking depending on the quality of the GPS data, Masters Thesis, The Czech Technical University in Prague, Prague, Czech Republic.

Hutt, O., Bowers, K., Johnson, S. D., \& Davies, T. (2018). Data and evidence challenges facing place-based policing. Policing: An International Journal,41(3), 339-351.

Knutsson, J., \& Clarke, R. (2006). Putting theory to work. Crime prevention studies (Vol. 20). Monsey: Criminal Justice Press.

Koper, C. S. (1995). Just enough police presence: Reducing crime and disorderly behavior by optimizing patrol time in crime hot spots. Justice Quarterly, 12(4), 649-672. https://doi.org/10.1080/07418829500096231.

Levine, R. V., \& Norenzayan, A. (1999). The pace of life in 31 countries. Journal of Cross-Cultural Psychology,30(2), 178-205.

Magdy, N., Sakr, M. A., Mostafa, T., \& El-Bahnasy, K. (2015). Review on trajectory similarity measures. In 2015 IEEE seventh international conference on 
intelligent computing and information systems (ICICIS) (pp. 613-619). New York: IEEE.

Merry, K., \& Bettinger, P. (2019). Smartphone GPS accuracy study in an urban environment. PLOS ONE, 14(7), e0219890.

Modsching, M., Kramer, R., \& Hagen, K. (2006). Field trial on GPS accuracy in a medium size city: The influence of built-up. In 3rd workshop on positioning, navigation and communication (pp. 209-218).

Mohler, G. O., Short, M. B., Brantingham, P. J., Schoenberg, F. P., \& Tita, G. E. (2015). Randomized controlled field trials of predictive policing. Journal of the American Statistical Association. https://doi.org/10.1080/01621 459.2015.1077710.

Novak, K. J., Fox, A. M., Carr, C. M., \& Spade, D. A. (2016). The efficacy of foot patrol in violent places. Journal of Experimental Criminology, 12(3), 465-475. https://doi.org/10.1007/s11292-016-9271-1.

Perry, W. L., McInnes, B., Price, C. C., Smith, S. C., Hollywood, J. S., \& Program, J. (2013). Predictive policing: The role of crime forecasting in law enforcement operations. Technical report, RAND. https://www.ncjrs.gov/pdffiles1/nij/ grants/243830.pdf.

Ratcliffe, J., Taniguchi, T., Groff, E. R., \& Wood, J. D. (2011). The Philadelphia foot patrol experiment: A randomized controlled trial of police patrol effectiveness in violent crime hotspots. Criminology,49(3), 795-831. https://doi. org/10.1111/j.1745-9125.2011.00240.x.

Rosser, G., Davies, T., Bowers, K. J., Johnson, S. D., \& Cheng, T. (2017). Predictive crime mapping: Arbitrary grids or street networks? Journal of Quantitative Criminology,33(3), 569-594.

Sherman, L. W. (1990). Police crackdowns: Initial and residual deterrence. Crime and Justice, 1, 1-49. https://doi.org/10.1086/449163.

Sherman, L. W., Buerger, M., \& Gartin, P. (1989). Beyond dial-a-cop: A randomized test of repeat call policing (recap). Washington, D,C: Crime Control Institute.
Sherman, L. W., \& Weisburd, D. (1995). General deterrent effects of police patrol in crime "hot spots": A randomized controlled trial. Justice Quarterly, 12(4), 626-648. https://doi.org/10.1525/sp.2007.54.1.23.

Snaterse, M., Ton, R., Kuo, A. D., \& Donelan, J. M. (2011). Distinct fast and slow processes contribute to the selection of preferred step frequency during human walking. Journal of Applied Physiology, 110(6), 1682-1690.

Sorg, E. T., Wood, J. D., Groff, E. R., \& Ratcliffe, J. (2014). Boundary adherence during place-based policing evaluations: A research note. Journal of Research in Crime and Delinquency,51(3), 377-393. https://doi.org/10.1177/00224 27814523789.

Telep, C. W., Mitchell, R. J., \& Weisburd, D. (2014). How much time should the police spend at crime hot spots? Answers from a police agency directed randomized field trial in Sacramento, California. Justice Quarterly,37(5), 905-933. https://doi.org/10.1080/07418825.2012.710645.

Tompson, L., Partridge, H., \& Shepherd, N. (2009). Hot routes: Developing a new technique for the spatial analysis of crime. Crime Mapping: A Journal of Research and Practice, 1(1), 77-96.

Weisburd, D., Groff, E. R., Jones, G., Cave, B., Amendola, K. L., Yang, S.-M., et al. (2015). The Dallas patrol management experiment: Can AVL technologies be used to harness unallocated patrol time for crime prevention? Journal of Experimental Criminology, 11(3), 367-391.

Williams, S., \& Coupe, T. (2017). Frequency vs. length of hot spots patrols: A randomised controlled trial. Cambridge Journal of Evidence-Based Policing, $1(1), 5-21$.

\section{Publisher's Note}

Springer Nature remains neutral with regard to jurisdictional claims in published maps and institutional affiliations.
Ready to submit your research? Choose BMC and benefit from:

- fast, convenient online submission

- thorough peer review by experienced researchers in your field

- rapid publication on acceptance

- support for research data, including large and complex data types

- gold Open Access which fosters wider collaboration and increased citations

- maximum visibility for your research: over $100 \mathrm{M}$ website views per year

At BMC, research is always in progress.

Learn more biomedcentral.com/submissions 